\title{
O Processo de Abstração Reflexionante na Construção de Conceitos Geométricos em Ambientes de Geometria Dinâmica
}

\author{
Margarete Farias Medeiros - IFC/ PPGIE - UFRGS \\ margarete.medeiros@sombrio.ifc.edu.br
}

\begin{abstract}
Resumo: O presente artigo expõe uma discussão sobre o processo de abstração reflexionante na construção de conceitos de Geometria Plana por meio de construções geométricas no software GeoGebra. Apresentam-se as vantagens do uso dessa tecnologia no ensino e aprendizagem, destacando os conceitos abordados na teoria de Piaget a partir de uma experiência realizada com acadêmicos do curso de Licenciatura em Matemática. Por meio das construções no software os participantes deveriam depreender o teorema utilizado para tal construção, permitindo ao observador analisar o processo de abstração reflexionante. A experiência proporcionou concluir que tecnologia digital facilita a interpretação das ações dos sujeitos quando a estão utilizando; o conhecimento da teoria de Piaget possibilita ao professor compreender os níveis em que o aluno se encontra; e que a abstração refletida, com tomada de consciência possibilita a construção do conhecimento científico.
\end{abstract}

\section{Palavras-Chave: Abstração Reflexionante, Geometria Dinâmica, Construções Geométricas.}

\section{The Process Reflective Abstraction in Geometric Concepts Construction in Dynamic Geometry Environments}

\begin{abstract}
The present article exposes an argument about the reflective abstraction process in the construction of concepts of plane geometry using geometric constructions in the GeoGebra software. We present the advantages of using this technology in the teaching and learning process, highlighting the concepts addressed in the Piaget theory from the experience performed with academics of mathematics graduation. Through the constructions in the software, the participants should infer the theorem used in such construction, allowing the observer to analyze the process of reflective abstraction. The experience allowed to conclude that digital technology eases the interpretation of actions of subjects when using it; the knowledge of the Piaget theory allows the teacher to comprehend the levels in which the student is; and that the reflected abstraction, with consciousness-making, enables the construction of scientific knowledge.
\end{abstract}

\section{Keywords: Reflective Abstraction, Dynamic Geometry, Geometric Constructions.}

\section{Introdução}

A tecnologia digital está presente nas diversas áreas do conhecimento e também na vida dos estudantes. Pesquisadores no Brasil e também no exterior (SILVA (2015), BASSO e NOTARE (2012), GRAVINA (2001), PAPERT (1994)) têm discutido sobre a inserção desta tecnologia no ambiente escolar, destacando o potencial que ela apresenta no ensino e aprendizagem. A grande parte destes estudos está sendo realizada com o objetivo de melhorar a aprendizagem dos conhecimentos científicos abordados na escola. Para tratar de aprendizagem de conceitos existe a necessidade de uma teoria que sustente este objetivo.

Neste viés, este artigo expõe uma discussão sobre a utilização de tecnologia para o ensino e aprendizagem, juntamente ao processo de abstração reflexionante, teoria de 
Piaget (1977/1995), a qual se apresenta como uma possibilidade de melhorar o ensino e aprendizagem da Matemática escolar. Pretende-se com o texto refletir sobre a construção, por parte dos estudantes, de conceitos de Geometria Plana à luz dos conceitos da Epistemologia Genética de Piaget, mais especificamente, sobre o processo de abstração reflexionante.

Para inserção da tecnologia na sala de aula utilizou-se o software GeoGebra, um ambiente de geometria dinâmica no qual foram construídas "Caixas Pretas" (Gravina, $2001)^{1}$, sendo que, a partir destas, os alunos deveriam, por meio do processo de abstração reflexionante, depreender o teorema ou as propriedades iniciais da construção.

No que segue apresentam-se reflexões sobre o processo de abstração reflexionante no desenvolvimento das construções no GeoGebra e a observação direta deste processo de abstração por três acadêmicos da oitava fase do curso de Licenciatura em Matemática quando submetidos à utilização das construções do tipo "caixa preta".

\section{O Processo de Abstração Reflexionante e as Construções no GeoGebra}

Quando se trata de aprendizagem busca-se uma teoria que sustente o ensino, um ensino fundamentado na ação do sujeito e, para isso, Piaget (1977/1995) contribui com sua teoria que abre caminhos para compreender este processo de entendimento, de compreensão, de construção de conhecimento. Ele mostrou, a partir de seu método clínico, como acontece o processo de abstração reflexionante, partindo da ação do sujeito sobre o objeto e na ação sobre si próprio. Antes de se tratar do processo de abstração reflexionante, no que segue, discute-se sobre a abstração empírica, abstração reflexionante pseudo-empírica e a abstração refletida, sendo conceitos abordados na teoria de Piaget (1977/1995), relacionando-os a exemplos de construções de Geometria Plana criados no GeoGebra, para se compreender o processo.

No GeoGebra tem-se a possibilidade de atribuir cor às construções, e a percepção da cor quando o sujeito entra em contato com o objeto, que neste caso, temse um objeto virtual, ele retira características do objeto, ou seja, daquilo que ele observa. Becker (2014, p.2) afirma que: "A abstração empírica consiste em retirar qualidades dos objetos, ou das ações em suas características materiais (...)". Neste sentido também se considera como abstração empírica, além da cor e forma das construções, o olhar ao movimento do objeto virtual na tela do computador, pois são observáveis. "Retirar características desses objetos ou ações, isto é, desses observáveis, qualifica as abstrações empíricas." (BECKER, 2014, p.3).

Já na abstração pseudo-empírica, que também é reflexionante, o sujeito retira dos objetos não mais suas características, mas das coordenações das ações do próprio sujeito, ou seja, quando ele observa, por exemplo, a posição de duas retas em uma construção no GeoGebra, e sob a ação da ferramenta "Mover" as retas preservam o paralelismo, o sujeito já está comparando as posições entre elas, e o paralelismo foi colocado pelo sujeito, pois ao considerar uma reta $\mathbf{r}$ ser paralela a uma reta $\mathbf{s}$, já estamos tratando de uma propriedade matemática criada pela humanidade. E esta atividade mental não pode ser observada, como afirma Becker (2014), apenas inferida a partir da observação do comportamento do sujeito.

Para Becker $(2014$, p.4) se o sujeito "retira dos observáveis não mais suas características, mas o que o sujeito colocou neles, tem-se, não mais uma abstração empírica, mas uma abstração reflexionante de tipo pseudo-empírica". De acordo com o autor, a abstração pseudo-empírica desempenha um papel fundamental, e, para Piaget 
(1977/1995, p.277) "ela serve de suporte e de auxiliar essenciais" no processo de abstração reflexionante.

A partir das construções feitas no GeoGebra, percebe-se como este ambiente propicia o processo de abstração reflexionante, pois o sujeito está em ação, ou seja, ele participa ativamente nas construções e, para Piaget (1958), é a partir da ação que o pensamento é impulsionado, e a abstração reflexionante é um processo que permite construir estruturas novas.

Na Figura 1 apresenta-se uma construção feita no GeoGebra, com a abertura de uma "Caixa Preta", na qual aparece a circunferência utilizada para sua construção e, a ao realizar as etapas de construção, o sujeito vai abstraindo, ou seja vai retirando as características dos "oberváveis" (abstração empírica) quando ele observa a cor do triângulo inscrito na circunferência, quando ele observa o movimento do triângulo o qual foi submetido a ação da ferramenta "Mover", faz abstração empírica, que tem certa importância. Mas, o significado é mínimo se comparado à abstração reflexionante pela qual o sujeito retira características das coordenações das ações (abstração pseudoempírica), quando ele observa que o triângulo construído preserva o ângulo de noventa graus (triângulo retângulo) e mantém seus vértices na circunferência, mesmo quando movimentado, com as quais constrói estrutura nova ou nova capacidade cognitiva em forma de teorema.

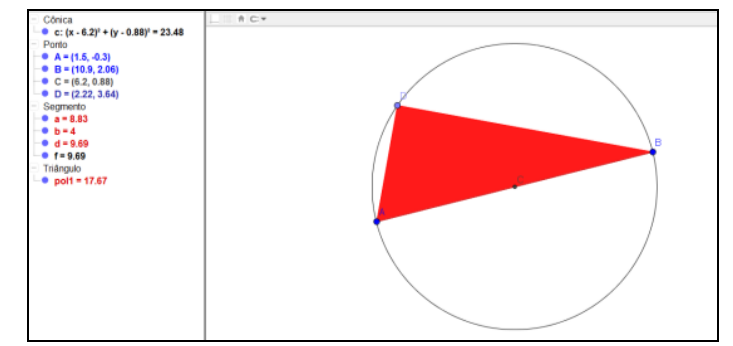

Figura 1. "Caixa Preta" aberta - Interface no GeoGebra

A partir destas abstrações o sujeito toma consciência de uma abstração reflexionante realizando, então, uma abstração refletida. Com ela o sujeito generaliza construções com as quais constrói o teorema assim formulado: "Se um triângulo inscrito em um círculo tem um lado igual ao diâmetro do círculo, então o triângulo é retângulo" (Figura 2). Tudo isso por uma sucessão de inumeráveis construções por reflexionamentos e reflexões. Este processo de abstração reflexionante, segundo Becker (2014,p.6) "acontece em dois momentos: os reflexionamentos e as reflexões".

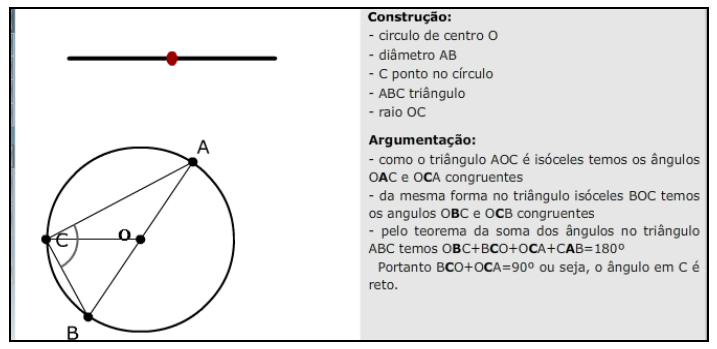

Figura 2. Teorema da Geometria Plana

Fonte: http://www.edumatec.mat.ufrgs.br/teoremasgeometria/TeoremasGeometriaplana.htm

Todo conhecimento científico implica a tomada de consciência, e de acordo com Becker (2014,p.5): "Pode-se dizer que todas as descobertas da humanidade, desde a pedra lascada, o fogo ou a roda, passando pelos teoremas de Euclides, até a lâmpada elétrica, (...), o cálculo diferencial e integral, (...) originaram-se de abstrações refletidas". 
No exemplo da Figura 1, considera-se que o sujeito teve uma abstração refletida e que, por reflexionamento, retirando as qualidades das coordenações de um patamar qualquer ele transfere a um patamar superior. No novo patamar, por reflexão, é realizada a reorganização do que foi transferido pelo reflexionamento, neste caso a generalização, o teorema, em função do que já existe neste patamar superior e, a partir desta reorganização, surge a novidade.

Becker (2014) afirma que esse processo de reflexionamentos e reflexões acontecem continuamente sendo que o reflexionamento pode ser interpretado como assimilação (ação do sujeito sobre o objeto) e a reflexão como acomodação (ação do sujeito sobre si mesmo). Essa união entre reflexão e reflexionamento é formadora de novos patamares:

Novos patamares de "reflexionamentos" constroem-se, portanto, sem cessar, para permitir as novas "reflexões" - é o que mostra toda a história das diferentes áreas das matemáticas, em suas tematizações sucessivas, até suas fases atuais. (PIAGET, 1977/1995, p.276).

A formação de cada novo patamar, acarreta por sua vez, novas reflexões, existindo uma forma sem interrupção de reflexionamentos e reflexões, dando origem a um processo em espiral. Neste sentido, Basso e Notare (2012) propõem o lançamento de desafios, os quais provocarão a necessidade de construção de novos conhecimentos, tendo como suporte os conhecimentos prévios dos estudantes, gerando este processo em espiral.

Para exemplificar este processo de reflexionamentos e reflexões, apresenta-se o processo de construção do "quadrado" no GeoGebra (Figura 3) e, a seguir, o desafio de abrir uma "caixa preta" (Figura 4).

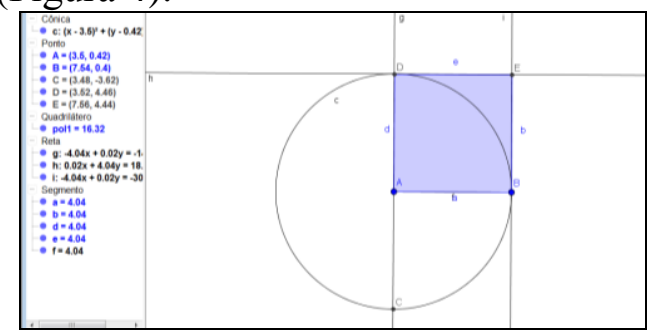

Figura 3. Construção do quadrado no GeoGebra

Considera-se que o processo de construção do "quadrado" configura um conhecimento prévio para a abertura da "caixa preta" (Figura 4). Na construção do "quadrado" o sujeito necessitou utilizar-se da definição da figura "quadrado", ou seja, quatro lados iguais conferidos a partir do raio da circunferência dada; lados paralelos conferidos pelas retas paralelas, e os quatro ângulos retos conferidos pelas retas perpendiculares. O sujeito submete à ação da ferramenta "Mover" e ele não se deforma, ou seja, conserva as propriedades iniciais da construção. Essa ação de construção da figura "quadrado" leva o sujeito a uma abstração refletida, quando toma consciência do que fez, se apropria do que fez. Por reflexionamento leva a um patamar superior, e por reflexão reorganiza este novo patamar com o que já existia ali. E qual a relação desta construção do "quadrado" com a abertura da "caixa preta" (Figura 4)?

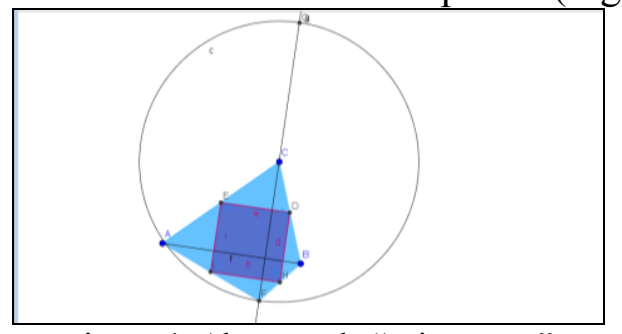

Figura 4. Abertura da "caixa preta" 
Neste sentido, considera-se que a construção do "quadrado" (primeiro desafio) serviu de conhecimento prévio para a abertura da "caixa preta" na Figura 4 (segundo desafio). Ao procurar abrir a "caixa preta" o sujeito observa em sua movimentação que algumas propriedades são preservadas, por exemplo, o quadrado inscrito no quadrilátero não se deforma e seus vértices são mantidos nos pontos médios dos lados do quadrilátero, e que as diagonais do quadrilátero são perpendiculares e congruentes (de mesma medida). Para efetuar estas construções, mantendo estas propriedades, foi utilizada a circunferência analogamente à construção do "quadrado" da Figura 3.

Pondera-se que neste patamar houve uma abstração refletida, o sujeito se apropriou do que se fez e por reflexionamento levou a um patamar superior e por reflexão acontecerá uma reorganização com o que já existe neste patamar, e assim ocorrerá continuamente, formando uma construção de conhecimento em espiral à medida que o sujeito for desafiado a abrir novas "caixas pretas".

\section{Uma Experiência com Construções Geométricas}

Nesta seção trata-se da observação direta do processo de abstração reflexionante de três acadêmicos ${ }^{2}$ da oitava fase do curso de Licenciatura em Matemática quando submetidos à utilização das construções do tipo "caixa preta".

A ideia foi observar o comportamento dos acadêmicos, visto que esse processo de abstração reflexionante é uma atividade mental e não pode ser observada apenas inferida a partir da observação do comportamento do sujeito (BECKER, 2014). Por isso, a observação de uma quantidade pequena de participantes, visto que a intenção era de se aproximar ao máximo dos sujeitos.

A experiência foi realizada no laboratório de Educação Matemática com a presença de três acadêmicos e a professora de Educação Matemática e Tecnologias, sendo que a mesma foi observadora do processo durante o encontro de aproximadamente três horas. Para contribuir na análise do processo solicitou-se aos acadêmicos que eles registrassem as ideias que iam surgindo durante a abertura da "caixa preta" e também enviassem os arquivos produzidos no GeoGebra. Esse material foi essencial para a análise confrontando com o comportamento dos acadêmicos.

A proposta consistiu em, a partir dos desafios de Geometria Plana propostos pela docente, observar-se o processo de argumentação e criação de ideias por parte dos sujeitos. Tais ideias tinham como objetivo construir uma explicação para os problemas de Geometria Plana.

Os acadêmicos foram submetidos à abertura de cinco caixas pretas, as quais são consideradas de um nível fácil a médio, cada uma delas estava relacionada a um teorema de Geometria Plana, sendo que eles deveriam fazer uma réplica da "caixa preta" apresentando uma escrita do teorema em questão. Os participantes tinham um nível intermediário de conhecimento em relação ao software GeoGebra; no encontro surgiram poucos questionamentos dos acadêmicos em relação às construções.

Nesta seção apresentam-se análises que evidenciam a tomada de consciência, ou seja, o momento da abstração refletida, e para tanto foram selecionados alguns dos apontamentos feitos pelos acadêmicos os quais apresentam as evidências em relação ao processo de abstração reflexionante. Os nomes dos participantes foram identificados pelas letras $\mathbf{C}, \mathbf{L}$ e $\mathbf{M}$, para facilitar na escrita.

$\mathrm{Na}$ primeira "caixa preta" (Figura 5), apresenta-se o teorema "Dado um triângulo $\mathrm{ABC}$ sempre existe um círculo passando pelos seus três vértices". Em suas

\footnotetext{
${ }^{2}$ Os acadêmicos do IFC- Campus Avançado Sombrio foram convidados para participar de uma experiência.
} 
anotações o acadêmico $\mathbf{C}$ observou que ao movimentar os vértices do triângulo eles se mantinham na circunferência, ou seja, estava inscrito na circunferência, e que ela circunferência aumentava ou diminuía.

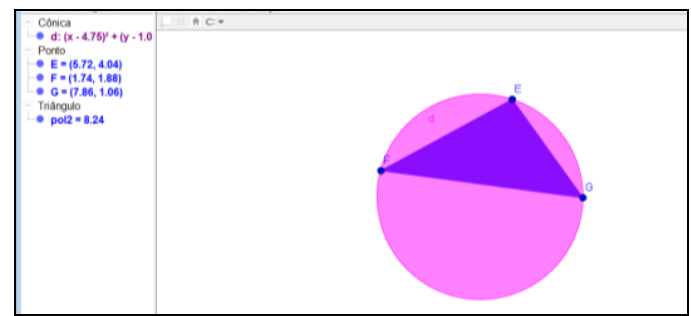

Figura 5. Caixa preta 1

Para sua construção no GeoGebra ele utilizou a ferramenta "Círculo definido por Três Pontos" e construiu um triângulo a partir destes três pontos, fez a réplica, mas não conseguiu explicar o porquê que essa propriedade era mantida, não conseguindo depreender o teorema. Observou-se que $\mathbf{C}$ ficou no nível da abstração empírica, diante dos observáveis, não conseguindo fazer generalizações para todos os triângulos. Já $\mathbf{L}$, registrou que " a mediatriz das retas que formam o triângulo, o ponto de encontro delas é sempre o raio da circunferência independente das medidas dos lados do triângulo, se esse triângulo estiver inscrito (...). Não lembro do teorema. Aqui evidencia-se que L, já utilizou a pseudo-empírica, porém ainda com certa fragilidade em sua conclusão, visto que possuía erros em sua escrita. Sua construção foi feita a partir de um triângulo inicial, com as mediatrizes relacionadas aos lados do triângulo e a construção do círculo com centro na interseção das mediatrizes passando pelos vértices do triângulo. Fez sua construção correta no GeoGebra, porém não generalizou para todos os triângulos. Considera-se que, neste momento, haveria a necessidade de intervenção, com perguntas do tipo: Isso acontecerá para todos os triângulos? Acredita-se que este questionamento poderia levar $\mathbf{L}$ a ter uma abstração refletida. $\mathbf{O}$ acadêmico $\mathbf{M}$ descreveu que acreditava que o triângulo inscrito foi feito a partir da ferramenta "Círculo definido por Três Pontos", e em seguida os três pontos foram ligados. M ainda afirma que esta configuração permite mover qualquer dos três pontos (os vértices do triângulo), ao mesmo tempo que define o tamanho do círculo, e com isso altera medidas de áreas, raio, diâmetro e lados do triângulo. Considera-se que $\mathbf{M}$ teve a abstração pseudo-empírica quando comparou as medidas, as quais estavam alterando quando ele movimentava a figura, porém não conseguiu ter a abstração refletida sem depreender o teorema a partir de sua escrita. Em sua construção observou-se que ele utilizou a ferramenta "Círculo definido por Três Pontos"; ligou os três pontos formando um triângulo, localizou o centro da circunferência e criou um segmento de reta ligando os vértices do triângulo ao centro. Em seguida, achou os pontos médios dos lados do triângulo e traçou três semirretas partindo do centro passando pelos pontos médios, e foi então que concluiu que essas semirretas eram perpendiculares aos lados dos triângulos, mas não conseguiu estabelecer que haviam retas suportes às semirretas, ou seja, as mediatrizes dos lados do triângulo. Acredita-se que se neste momento houvesse a intervenção de um questionamento quanto às semirretas traçadas ele pudesse chegar à abstração refletida e conseguir estabelecer o teorema utilizado para a construção da "caixa preta".

Na segunda "caixa preta" (Figura 6) a construção seguiu o teorema: "Se um segmento tem extremidade nos pontos médios de dois lados de um triângulo, então ele é paralelo ao terceiro lado e tem metade do comprimento do terceiro lado."

$\mathrm{O}$ acadêmico $\mathbf{C}$ descobriu como abrir a "caixa preta" por meio das ferramentas do GeoGebra e avisou a professora, no entanto disse que não iria usar as informações de construção contidas no "Protocolo de Construção". 


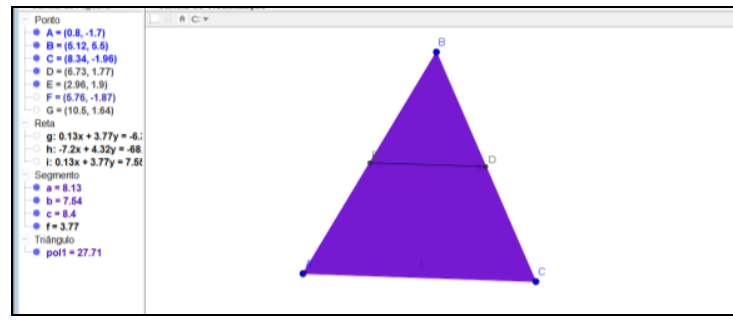

Figura 6. Caixa Preta 2

Sua escrita comprova que foi verdadeira sua afirmação, pois ele registra que se utilizou do Teorema de Tales, observou que existiam triângulos proporcionais, e estas ideias estão apresentadas em sua construção no GeoGebra. Entretanto, ainda não obteve a abstração refletida com tomada de consciência. Nessa construção sua abstração foi a pseudo-empírica quando comparou os triângulos formados e a relação ao teorema de Tales. $\mathrm{O}$ acadêmico $\mathbf{L}$, em sua escrita trabalha com retas paralelas e ângulos colaterais externos congruentes, e afirma que:"as retas paralelas que cortam o triângulo com uma delas passando pelos pontos médios de dois lados formam duas bases sendo uma o dobro da outra". Em sua construção observamos que $\mathbf{L}$ construiu de acordo com sua escrita e obteve uma abstração refletida quando conseguiu estabelecer o teorema que fundamentou a construção da "caixa preta", generalizando para todos os triângulos e tomando consciência de suas ações. $\mathrm{O}$ acadêmico $\mathbf{M}$ apresenta, em sua descrição, no triângulo em dois de seus três lados foram definidas as "medianas", escreveu "mediana" e pensou como "ponto médio", e disse que a partir das "medianas" foi traçado um segmento $\overline{\mathrm{ED}}$. Ele afirma que está presente nesta construção o teorema de feixes de retas paralelas cortados por duas transversais e apresenta um desenho representando sua escrita. Além disso, ele também se refere aos ângulos correspondentes que mantêm suas medidas mesmo sob a ação de movimentos. Não conseguiu apresentar qual foi o teorema utilizado na construção, mas levantou o teorema do feixe de retas paralelas cortados por transversais, ou seja, aqui houve uma abstração refletida em relação aos conceitos matemáticos.

Na terceira "caixa preta" (Figura 7) apresenta-se o teorema: "Em um triângulo o ponto da interseção de duas medianas divide as medianas na razão 1:2".

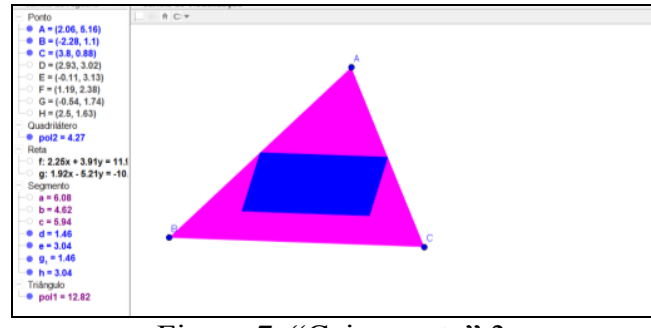

Figura 7. "Caixa preta" 3

$\mathrm{O}$ acadêmico $\mathbf{C}$ escreve que não conseguiu reproduzir a construção da "caixa preta" e que, mesmo depois de ver por duas vezes como ele foi construído (abriu a caixa preta pela ferramenta do GeoGebra), não conseguiu construir de acordo com o que havia visto. Neste caso, considera-se que $\mathbf{C}$ obteve a abstração empírica quando observou as cores e o movimento da construção, e que obteve a pseudo-empírica quando em sua fala, disse que conseguia ver que a figura no interior tratava-se de um paralelogramo e que dois de seus vértices estavam localizados nos pontos médios em dois lados do triângulo, porém não conseguiu ir adiante.

$\mathrm{O}$ acadêmico $\mathbf{L}$, também descreveu o paralelogramo: "encontram-se no ponto médio - superiores", que no nosso entendimento dois vértices do paralelogramo estão localizados nos pontos médios de dois lados do triângulo. $\mathbf{L}$ fala em bissetrizes, porém 
na construção não temos bissetrizes, e sim medianas. Observou-se que, na sua produção, ele comparou áreas de triângulos e trapézio, formados internamente ao triângulo $\mathrm{ABC}$, sendo que neste caso trata-se de uma abstração pseudo-empírica e que $\mathbf{L}$ não conseguiu depreender o teorema proposto na construção. $\mathrm{O}$ acadêmico $\mathrm{M}$ faz uma descrição bem detalhada de suas ações destacando que foi construído um triângulo, encontrando os pontos médios de dois lados e "achou" uma reta paralela à base. Em seguida foi traçado um segmento de reta que une os pontos médios aos vértices das bases (as medianas), sendo encontrado o ponto de interseção destes dois segmentos e encontrado as "medianas" (neste caso M confunde novamente o conceito de mediana e ponto médio, aqui ele se refere ao ponto médio). A seguir, encontra os pontos médios entre o ponto de interseção e os vértices da base do triângulo e diz que é possível construir um paralelogramo com os pontos médios encontrados. Ele afirma: "Não sei dizer qual o teorema que estou aplicando (...) quando estou descrevendo o passo a passo da construção dessa figura, também estou descrevendo o teorema". Na sua fala ele aponta as distâncias entre os pontos e percebe-se que $\mathbf{M}$ conseguiu abstrair refletidamente, ou seja, tomou consciência do que fez. Esta construção foi classificada pelos acadêmicos como um nível difícil e que para construí-la, L e M, utilizaram-se de alguns fundamentos da "caixa preta" 3 (Figura 6). Aqui verifica-se a necessidade dos conhecimentos prévios e também encontram-se evidências do processo de abstração reflexionante.

Para a "caixa preta" 4 (Figura 8) utilizou-se o teorema: "Os pontos médios dos lados de um quadrilátero qualquer são vértices de um paralelogramo". Apresentou-se esta construção com a ideia de que o sujeito poderia utilizar-se da segunda "caixa preta" para abrir esta, e a partir das falas dos acadêmicos percebeu-se que isso ocorreu.

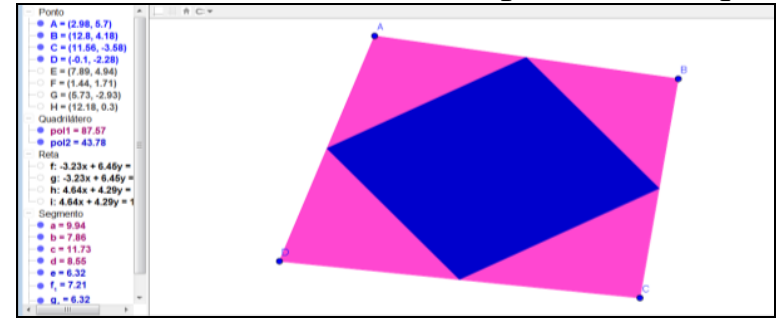

Figura 8. Caixa Preta 4

$\mathrm{Na}$ escrita de $\mathbf{C}$, ele descreve que, primeiramente, foi construído um quadrilátero qualquer e após foi "descoberto" o ponto médio de cada lado para, em seguida, ligar os quatro pontos médios formando outro quadrilátero, que classificou como paralelogramo. Sua construção comprova o que escreveu. Quando mostrou sua construção perguntouse: o que comprovava que a figura inscrita no quadrilátero qualquer era um paralelogramo? Ele se referiu ao teorema da "caixa preta" 3 como fundamento para responder ao questionamento. $\mathrm{O}$ acadêmico $\mathbf{L}$ também fez a generalização e depreendeu o teorema escrevendo-o: "Em um quadrilátero qualquer ao traçar os pontos médios obtêm-se sempre um paralelogramo”. Sendo que sua construção comprovou sua escrita. $\mathrm{O}$ acadêmico $\mathbf{M}$ escreve que "A união dos pontos médios de um quadrilátero dá origem a outro quadrilátero e assim sucessivamente". Por esta fala percebeu-se que M generalizou, afirmando que isso sempre acontecerá. E, somente depois, ele afirma que não tinha percebido que o quadrilátero inscrito era um paralelogramo. Sua construção apresenta exatamente o que ele escreveu. Aqui se evidencia a abstração refletida com tomada de consciência dos três participantes com os dois momentos, o reflexionamento e a reflexão, ou seja, caracterizando o processo de abstração reflexionante.

$\mathrm{Na}$ última "caixa preta" (Figura 9) o teorema para sua construção foi o enunciado na Figura 2: "Se um triângulo inscrito em um círculo tem um lado igual ao 
diâmetro do círculo, então o triângulo é retângulo". Essa "caixa preta" foi escolhida com o objetivo de verificar se os acadêmicos iriam utilizar-se dos conhecimentos construídos com a primeira "caixa preta", ou seja, os conhecimentos prévios, visto que foi utilizada a circunferência para a sua construção.

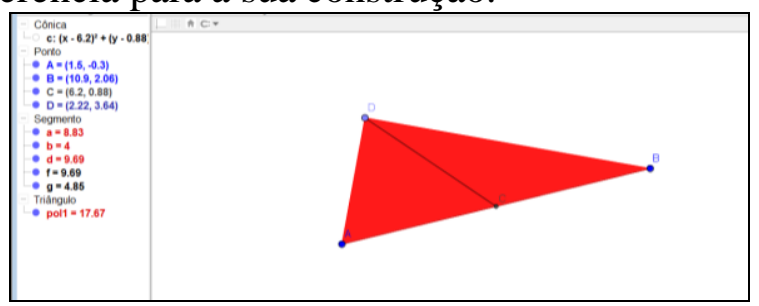

Figura 9. Caixa preta 5

Na sua escrita, o acadêmico $\mathbf{C}$, trata o segmento $\overline{\mathrm{DC}}$ como altura de forma equivocada. Será que este acadêmico tem o conceito de altura construído corretamente? Suas conclusões seguintes estão corretas. Afirma que: "A altura $\overline{\mathrm{DC}}$ é igual ao comprimento de $\overline{\mathrm{CB}}$ e que é igual a $\overline{\mathrm{AC}}$, porque os segmentos $\overline{\mathrm{BA}}$ forma o diâmetro de uma circunferência." Porém, não afirma que o triângulo formado é retângulo. Sua construção está de forma correta, sendo que o acadêmico habilitou o rastro de um ponto de sua construção descrevendo uma circunferência. Não generalizou para que todos os triângulos construídos desta forma fossem retângulos, portanto ele pode ter tido uma abstração pseudo-empírica.

$\mathrm{Na}$ escrita de $\mathbf{L}$, observamos que ele percebe que o triângulo formado é retângulo, também que o segmento $\overline{\mathrm{DC}}$ divide o triângulo $\mathrm{ABD}$ em dois triângulos isósceles, e que o triângulo $\mathrm{ABD}$ está inscrito em uma circunferência. Porém, L não destaca o teorema. Sua construção apresenta o triângulo inscrito na circunferência obedecendo ao teorema em questão. L também ficou na abstração pseudo-empírica.

$\mathrm{O}$ acadêmico $\mathbf{M}$ escreve que: "A partir do segmento de reta do diâmetro de um círculo, é possível traçar um triângulo ligando os dois pontos de interseção do diâmetro com a circunferência, a um terceiro ponto localizado a qualquer ponto da circunferência, distintos das interseções anteriores, assim teremos um triângulo inscrito na circunferência." Observou-se que M percebe que um dos lados do triângulo é o diâmetro da circunferência contendo dois vértices, e que o terceiro vértice do triângulo movimenta-se sobre a mesma circunferência. Verificou-se esta afirmação em sua escrita e construção, porém em nenhum dos registros encontrou-se a ideia de que o triângulo formado era triângulo retângulo. Portanto, ele não conseguiu ter uma abstração refletida, somente uma abstração pseudo-empírica. Ao término da atividade os acadêmicos foram questionados quanto à classificação daquele triângulo formado, sendo que $\mathbf{L}$ respondeu que era escaleno, os demais não se manifestaram; e quanto aos ângulos, todos responderam que se tratava de um triângulo retângulo. A partir deste questionamento os acadêmicos verificaram o teorema.

\section{Considerações Finais}

A partir das leituras e da experiência de pesquisa relatada neste artigo busca-se apresentar reflexões que possam ser utilizadas no aperfeiçoamento do ensino e, consequentemente, na aprendizagem dos estudantes da Educação Básica. Primeiro que a tecnologia digital facilita a interpretação, por parte do professor, das ações dos sujeitos quando a estão utilizando. Por exemplo, o GeoGebra permite ao professor verificar todos os passos trilhados pelo aluno para desenvolver uma construção. Também se destaca o ambiente de geometria dinâmica, o qual permite manter as propriedades 
iniciais da construção, e isso faz com que o aluno visualize a mesma construção em tamanhos diferentes. Além disso, o potencial que ela representa em relação às metodologias do tipo quadro e giz.

Em segundo lugar destaca-se a teoria de Piaget (1977/1995) e apresentada por Becker (2014) quanto ao processo de abstração reflexionante. O conhecimento dessa teoria possibilita ao professor compreender os níveis em que o aluno se encontra e, também, se ele está tendo só abstrações empíricas, ou seja, permanece nas características observáveis e, que se o aluno ficar somente nestas, ele não estará construindo conhecimento. De que existe a necessidade de abstrações reflexionantes, do tipo pseudo-empíricas, para que o aluno possa retirar qualidades de suas coordenações de ações e tomar consciência dessas abstrações chegando às abstrações refletidas. Constrói assim conhecimento científico, como por exemplo, na Matemática chegar à generalização de suas construções em forma de teorema.

$\mathrm{Da}$ experiência com os acadêmicos destacam-se as falas finais quando questionados sobre as atividades realizadas utilizando o software. Os três participantes afirmaram que foi uma atividade importante, que não se lembravam dos teoremas tratados nas "caixas pretas" e de que o uso da tecnologia facilita a compreensão, mas também questionaram: por que professores da área da Matemática não a utilizam? Existem muitas dificuldades para utilizar nas escolas? Faltam computadores nas escolas? E assim foram os questionamentos. Considera-se que é a partir destas experiências que muitas destas questões podem ser respondidas.

\section{Referências}

BASSO, Marcus V. A. e NOTARE, Marcia. Tecnologia na Educação Matemática: Trilhando o Caminho do Fazer ao Aprender. In: RENOTE. v. 10. n.3. CINTEDUFRGS, 2012.

BECKER, Fernando. Abstração pseudo-empírica e reflexionante: Significado epistemológico e educacional. In: Schème - Revista Eletrônica de Psicologia e Epistemologia Genéticas. V. 6. UNESP, 2014.

GRAVINA, Maria Alice. Os ambientes de geometria dinâmica e o pensamento hipotético-dedutivo. Tese de Doutorado, Porto Alegre: UFRGS, 2001.

GRAVINA, Maria Alice; FERREIRA, Carlos Eduardo Souza. Teoremas da Geometria Plana usando animações. Disponível em: < http://www.edumatec.mat.ufrgs.br/teoremasgeometria/TeoremasGeometriaplana.htm>. Acesso em 21.set.2016.

PAPERT, Papert, Seymour M. A Máquina das Crianças: Repensando a Escola na Era da Informática. Porto Alegre, Artes Médicas, 1994.

PIAGET, Jean. [1977] Abstração Reflexionante: relações lógico-aritméticas e ordem das relações espaciais. Tradução: Fernando Becker e Petronilha Beatriz Gonçalves da Silva. Porto Alegre: Artes Médicas, 1995.

SILVA, Rodrigo Sychocki. Cadeias de Markov e Modelagem Matemática: da Abstração Pseudo-empírica à Abstração Refletida com Uso de Objetos Virtuais. Tese de Doutorado, Porto Alegre: UFRGS, 2015. 